\title{
A few words on the creation of the cover image
}

I was pleased and delighted to be asked to create the cover image for this Research Handbook on Energy and Society. The method I have used is that of digital collage, which seemed to me the perfect vehicle for this project, as it is done by building up layers of images and varying their position and opacity to allow elements to shine through and overlap one other - and surely that is the nature of both the technological development of energy generation and the growth of society.

It is also not lost on me that, but for energy, I would not have been able to take, edit or store the images I've used.

I've also added a couple of family images, one of my now deceased mother-in-law as a young woman in the late 1940s, and one of me and my siblings around 1963. We were perhaps the last generation to experience single glazing, coal fires at home, and milk delivered by horse and cart at a time of preparations for a moon mission.

The demolition of Cockenzie power station, which in my lifetime had gone from the energy hub of the Lothians to a mothballed end-of-an-era facility, is also included. The bike photo is of University of Edinburgh bikes, set up to generate electricity, which were being used by the public at an art and science event high up on North Berwick Law, so there was a pleasing synchronicity in using it here.

Many thanks to Jan for asking me to assist with the cover image for this important publication.

Anna K. Dickie 